\title{
PENSATA
}

Submetido 29.07.2020. Aprovado 05.01.2021

Avaliado pelo sistema double blind review. Editor Científico convidado: Alcides Barrichello

Versão original | DOI: http://dx.doi.org/10.1590/So034-759020210407

Renata Couto de Oliveira ${ }^{1}$ | renatacouto@yahoo.com | 00oo-0001-5839-8814

${ }_{1}^{1}$ Universidade do Grande Rio, Escola De Ciências Sociais Aplicadas, Rio de Janeiro, RJ, Brasil

\section{GAMIFICAÇÃO E TRABALHO UBERIZADO NAS EMPRESAS-APLICATIVO}

Uberização, gig economy, on-demand economy, economia de plataforma e crowdsourcing são exemplos de termos usados em diversos trabalhos acadêmicos para se referir ao grande número de transformações promovidas pelas tecnologias de comunicação e informação (doravante abreviado como "TCl”) nos universos das organizações e do trabalho, sem que haja consenso sobre seus significados (Filgueiras \& Antunes, 2020, p. 30). 0 termo "uberização" (Slee, 2017) remete diretamente à Uber, porém não se restringe a ela, sendo usado em sentido amplo como uma tendência global que atinge ocupações com diferentes qualificações e rendimentos, materializando processos e subjetividades associados à nova razão neoliberal do mundo (Dardot e Laval, 2016). A socióloga Ana Claudia Moreira cunhou a expressão “uberismo" para se referir a um modelo de organização e gestão do trabalho, tal qual taylorismo, fordismo e toyotismo, que surgiu no lastro das $\mathrm{TCl}$ e das plataformas (Santos, 2020). Além da Uber, são exemplos de "empresas-aplicativo" (Abílio, 2019) Loggi, iFood, Rappi e Lyft.

Inicialmente as transformações promovidas pelas $\mathrm{TCl}$ ofereciam inúmeras oportunidades aos trabalhadores, por exemplo, a ausência de rigidez dos empregos tradicionais, permitindo que as pessoas acumulassem atividades e gerassem renda extra. A geração de renda aconteceria supostamente de modo divertido no tempo livre do prestador do serviço (Stefano, 2017), ou quando aquele bem entendesse e desejasse (Valenduc, 2019), por meio da sua atuação ou como criador, ou como parceiro da empresa-aplicativo. Outra vantagem do modelo de plataforma é a redução da distância espacial entre as oportunidades de renda e os trabalhadores, que podem exercer as atividades independentemente da sua localização geográfica (Kittur et al., 2013), como no caso da plataforma de microtrabalho Amazon Mechanical Turk (Moreschi, Pereira, \& Cozman, 2020). A distância tornou-se menor também entre provedores de serviços e consumidores graças às plataformas digitais e aos aplicativos, reduzindo preços e agilizando a prestação de uma gama enorme de serviços (Manyika et al., 2016) de transporte, estética, limpeza e serviços gerais, entregas, entre outros. Mais vantagens figuram nesse rol, como a democratização dos meios de produção e o fomento ao neoempreendedorismo (com oportunidades para pequenos negócios, como citam Filgueiras e Antunes, 2020).

Apesar do entusiasmo inicial associado à autonomia, às oportunidades econômicas e à equidade (Schor \& Eddy, 2020) promovidas pelas plataformas digitais, o contexto atual, principalmente o da pandemia de Covid19, apontou para a dependência de alguns serviços, como o de entregas, além de mostrar que, apesar de alguns resultados positivos, muitos trabalhadores que atuam nessas condições sofrem as consequências negativas da economia de plataforma. Essa nova economia é capitaneada por startups que se definem como empresas de tecnologia e intermediárias entre consumidores e produtores/prestadores de serviços (Filgueiras \& Antunes, 2020), 
estruturando-se a partir de um modelo capitalista extrativista (Morrell, Espelt, \& Cano, 2020). Contrastam com as oportunidades citadas no parágrafo anterior os baixos salários e falta de autodeterminação (Schor \& Eddy, 2020), além de longas jornadas de trabalho, da transferência dos custos e riscos associados às atividades para os trabalhadores, que ainda precisam ser geridos, controlados e subordinados (Abílio, 2019) após aderirem aos termos e condições de uso das plataformas. Em um contexto como esse, no qual fontes e estruturas de significados (como práticas, valores, rituais e hierarquias, por exemplo) são influenciados, criados ou expressos pelas TCl (Kozinets, 2019, p. 621), a gamificação emerge como uma das ferramentas que as plataformas digitais utilizam para controlar, gerenciar e vigiar seus "parceiros".

Nos últimos oito anos, a "gamificação" tomou as organizações, a mídia e as pesquisas acadêmicas de assalto (e.g. Dymek \& Zackariasson, 2016a). Uma busca no Google Scholar aponta cerca de 51 mil resultados sobre o tema entre 2002 e 2020. Neste ano (2020), destacamos o trabalho de Doorn e Chen (no prelo), que versa sobre a gamificação no contexto de duas plataformas de entrega de comida, uma chinesa e outra norte-americana; e o de Abílio, que define gamificação como a "transferência de riscos e em estímulos à produtividade, que também são novas formas de controle sobre o trabalho” (Abílio, 2020, p. 20), uma forma-desafio lançada a quem se arrisca trabalhando, sem nenhuma garantia, uma vez que cabe à empresa-aplicativo definir as regras do jogo e, possivelmente, o vencedor (o que sugere que, em vez da aleatoriedade algorítmica, há uma distribuição programada de bonificações, por exemplo). 0 objetivo mais imediato da gamificação é promover o engajamento de trabalhadores e consumidores por meio de desafios e competições baseados em desempenho e incentivos e, em decorrência disso, obter melhores resultados (Dymek \& Zackariasson, 2016b). A definição seminal de Deterding, Khaled, Nacke e Dixon (2011) inspirou autores como Woodcock e Johnson (2018) a apreenderem gamificação como a aplicação de sistemas de jogos (competição, prêmios, quantificação do comportamento do usuário) em domínios que não têm relação com aqueles, como no trabalho.

Nesta pensata, analisamos a relação entre gamificação e trabalho uberizado no bojo das empresas-aplicativo, plataformas digitais (Srnicek, 2017) que representam um novo modelo de negócio com infraestrutura vinculada às $\mathrm{TCl}$ e aos algoritmos. Partimos de uma posição crítica sobre esses temas, uma vez que a gamificação é comumente abordada pela literatura gerencialista como uma estratégia capaz de promover engajamento e aumentar o desempenho dos funcionários, promovendo satisfação em uma espécie de win-win situation para organizações e seus colaboradores. Como a gamificação também apresenta grande potencial de solucionar problemas que podem ser resolvidos influenciando a motivação e o comportamento humano (Zichermann \& Cunningham, 2011), nos perguntamos quais seriam os desdobramentos da união entre essa estratégia e o uberismo em um contexto no qual a precariedade do trabalho se associa ao capitalismo de vigilância (Zuboff, 2015) e à governança algorítmica (Castro, 2018). Assim, visamos discutir a gamificação como uma ferramenta de gestão, controle e subordinação do trabaIho, associada também à opacidade algorítmica (Bridle, 2019), à manutenção da multidão de trabalhadores e à figura do trabalhador just in time (Abílio, 2019). Por fim, destacaremos sucintamente algumas opções à economia de plataforma tradicional que podem minimizar o uso da gamificação, como a possibilidade de economia de plataforma sustentável e o cooperativismo de plataforma (Morrell et al., 2020; Scholz, 2016; Schor \& Eddy, 2020).

\section{GAMIFICAÇÃO E PLATAFORMAS}

Em 2002, o termo "gamificação" surge como o processo por meio do qual métodos, metáforas, valores e atributos de jogos permeiam nossa sociedade (Fuchs, 2014). Placas de funcionário do mês e programas de fidelidade 
são exemplos de gamificação pré-digital (Vesa \& Harviainen, 2019). Por um lado, essa estratégia é exaltada como uma solução divertida para engajar e motivar consumidores e trabalhadores (McGonigal, 2011). Assim, as estruturas, organizações ou sistemas tornam-se mais intrinsecamente motivadores, apoiando a criação geral de valor (Vesa, Hamari, Harviainen, \& Warmelinl, 2016). Por outro lado, surgiram críticas e dúvidas sobre a gamificação, questionando sua eficácia sem motivação preexistente (e.g. Hamari, 2013) e a duração de seu efeito em longo prazo (e.g. Koivisto \& Hamari, 2014).

A diferença proposta por Caillois (2001/1958) entre ludus (formas mais explícitas de jogos orientados por regras, sem conotação negativa) e paida (jogo livre, improvisação, espontaneidade e impulsividade) orientou algumas dessas críticas. Por exemplo, Bogost (2011) cunhou a expressão exploitationware como sinônimo de gamificação, enquanto Escribano (2013) afirma que a gamificação não passa de uma "ditadura lúdica”. Woodcock e Johnson (2018) destacam dois tipos distintos de gamificação: a vinda de cima (gamification-from-above), associada ao conceito de ludus, enfatizando formas de interação e feedbacks desenhados a partir de jogos, mas separados de seus contextos lúdicos originais, e a vinda de baixo (gamification-from-below), identificada com contextos lúdicos associados à paida e que teriam por escopo tornar a realização do trabalho mais fácil e, em certos momentos, servir como prática de resistência. A gamificação do trabalho parece orientá-lo através de um viés comportamental, virtual e instrumental, tornando-o um jogo competitivo e (em tese) divertido, retribuindo trabalhadores com recompensas de prestígio imaterial (Vesa et al., 2017), como distintivos virtuais (badges) de excelência de serviço e de motorista divertido, como no caso da Uber (Scheiber, 2017).

Nosso posicionamento é que a gamificação associada ao trabalho uberizado das empresas-aplicativo resulta na intensificação e na exploração do trabalho, evidenciando a nova forma que as práticas de gestão, controle e vigilância assumem no contexto tecnocultural. Nesse sentido, a promessa utópica da sociedade da informação de inserção social emancipada no e pelo trabalho desmorona (Braga, 2009, p. 65). A gamificação se cristaliza por meio da uberização do trabalho, sendo difícil identificá-la, pois ela não se materializa em um espaço disciplinar (como uma fábrica). Tudo ocorre por meio dos aplicativos, com ínfimo contato humano e de maneira automatizada. A vigilância ostensiva torna-se um elemento fundamental para a eficácia da gamificação e é viabilizada pelas plataformas digitais, que atuam como intermediários entre a oferta de trabalho e a demanda de serviço, exibindo tendências de monopólio decorrentes dos efeitos de rede (quanto maior o número de usuários, mais valiosa a plataforma e melhores seus algoritmos) (Srnicek, 2017). Assim, ao pensarmos sobre gamificação, devemos atentar ao escopo dessa estratégia vis-à-vis o processo do trabalho nas empresas-aplicativo.

Sabemos que o capitalismo se reestrutura de tempos em tempos e que, desde 2008, sua última versão está associada a uma narrativa focada na mudança e na ascensão da tecnologia, e que, desde então, vivemos numa economia informacional que o autor denomina "economia de plataforma”, caracterizada pela extração e uso de uma nova forma de matéria-prima: dados (Srnicek, 2017). Dizer que os dados são o petróleo do século XXI pode ser um clichê, mas, levando em consideração a escala das transformações digitais em andamento, não podemos subestimá-lo (Morozov, 2018, p. 8). De modo similar ao petróleo, os dados devem ser extraídos e refinados para então serem usados. Esse processo envolve sua captação, seu registro em algum tipo de mídia material e sua manutenção em sistemas de armazenamento maciço (Srnicek, 2017). As plataformas são projetadas para governar as possibilidades de interação, sendo as regras de desenvolvimento de seus produtos e serviços definidas pelo seu proprietário, o que indica que ela não é um espaço vazio nem apolítico (Srnicek, 2017).

O próprio termo "plataforma" institui um modo de ser que sanciona um estado particular das coisas, enquadrando discursivamente os serviços e tecnologias de empresas no contexto de demandas financeiras, culturais e 
regulatórias (Gillespie, 2010, p. 349). Esse enquadramento é estratégico, pois posiciona as empresas-aplicativo na busca de lucros atuais e futuros em um ponto regulatório entre as proteções legislativas que as beneficiam e as obrigações que não as beneficiam, apresentando um imaginário cultural no qual seus serviços fazem sentido aos seus usuários e à sociedade como um todo (Gillespie, 2010, p. 348). Assim, as plataformas estabelecem "os próprios critérios pelos quais essas tecnologias serão julgadas” (Gillespie, 2010, p. 359), assumindo a forma de “um arranjo progressivo e igualitário, [que promete] apoiar aqueles que a sustentam” (Gillespie, 2010, p. 350).

\section{VIGILÂNCIA E GOVERNANÇA ALGORÍTMICA DO TRABALHADOR JUST IN TIME}

A coleta e a análise de dados devem ser entendidas como "um processo dinâmico no qual sistemas de vigilância e criação de perfis e informações pessoais informam-se continuamente a cada nova interação entre os sistemas e consumidores" (Pridmore \& Zwick, 2011, p. 272). Como resultado, as empresas-aplicativo customizam e estruturam o mundo de maneira pouco transparente (Morozov, 2018, p. 53), por meio da "mineração da realidade" (reality mining, Zub off [2015]). Extrapola-se o mero saber sobre o que as pessoas fazem todo o tempo, criando-se a possibilidade de intervenção e alteração do comportamento de modo que "o que é real e o que é resultado da manipulação tecno-cibernética em tempo real se torne indistinguível” (Charitsis, Zwick, \& Bradshaw, 2018, p. 822). Isso se aplica também aos "parceiros" das empresas-aplicativo, que são, ao mesmo tempo, consumidores das TCl empregadas por elas e trabalhadores que aderem (grifo nosso) a ela (uma vez que não é firmado um contrato entre as partes).

A operação das plataformas digitais foi viabilizada, entre outros fatores, pelo cenário tecnocultural e operações associados ao capitalismo de vigilância (Zuboff, 2015), nos remetendo, assim, ao conceito de sociedade de controle e à “implantação progressiva e dispersa de um novo regime de dominação” (Deleuze, 1992, p. 225). O capitalismo de vigilância instaura um regime institucional ubíquo, um novo tipo de mão invisível, denominado Big Other, que aniquila as liberdades conquistadas por meio da instituição do Estado de direito, configurando-se como um "regime de fatos independentes e independentemente controlados que suplanta a necessidade de contratos, de governança e o dinamismo de uma democracia de mercado" (Zuboff, 2015, p. 81). 0 futuro adaptado à normalização do caos e do terror é o que emerge em substituição à "comunidade de iguais vinculados pelas leis na inevitável e, em última análise, frutífera luta humana contra a incerteza” (Zuboff, 2015, p. 81). A previsão de Zuboff contempla também a instauração de um sistema de conformidade baseado em recompensas e punições que contribui para a acumulação "não apenas de capital e ativos de vigilância, mas também de direitos" (Zuboff, 2015, p. 83), na medida que os direitos individuais seriam tomados dos indivíduos pelo Big Other e, posteriormente, redistribuídos unilateralmente por ele.

Apesar do que afirma Zuboff (2015) sobre ausência de governança, Castro (2018) aponta "uma nova forma de governança exercida pelas organizações através de algoritmos” (Castro, 2018, p. 169, itálico no original) que mineram (data mining) grandes volumes de dados e metadados (daí o termo big data) capturados por meio das atividades mediadas pelas empresas-aplicativo. Trata-se da governança algorítmica que reflete uma generalização dos instrumentos de gestão, criando uma espécie de governo sem governo e distanciando-se da ideia de governo como administração estatal, privilegiando, assim, estilos de comando horizontais ou em rede (Castro, 2018, p. 169). Destacamos, ainda, que a governança algorítmica encontra esteio no ponto de vista tecnocrático, segundo o qual "as decisões políticas baseiam-se em fatos neutros ou argumentos racionais" (Lemke, 2007, p. 54). Tal constatação nos remete aos trabalhos de Gillespie (2010) e Srnicek (2017) sobre como as plataformas se instituem, inclusive discursivamente, como empresas de tecnologia mediadoras entre demanda e oferta. Ressal- 
tamos, ainda, que, associada a essa instituição, está a opacidade das $\mathrm{TCl}$ e seus algoritmos, esses entendidos como um conjunto de instruções para realizar uma tarefa e cada vez mais incumbidos de decisões, avaliações e análises que impactam diretamente nossas vidas (Doneda \& Almeida, 2018, p. 141).

O trabalho algorítmico é tão complexo que a ele é atribuída a opacidade tecnológica, uma vez que o algoritmo em si é dotado de aprendizagem automática, sendo capaz de tomar sozinho a decisão "de reorganizar seu funcionamento interno com base nos dados que está analisando” (Doneda \& Almeida, 2018, p. 142). Nesse sentido, fala-se em “opacidade dos sistemas tecnológicos” (Bridle, 2019, p. 132), ou seja, a atuação contemporânea da tecnologia produz efeitos no mundo real que são quase imperceptíveis a priori e, portanto, mais difíceis de serem dimensionados por nós (Bridle, 2019, p. 137). No contexto do uberismo, é comum que trabalhadores não apreendam o funcionamento de diversas atividades que fazem parte de suas rotinas, como o preço dinâmico, os desligamentos promovidos pelas plataformas, a distribuição de corridas e tarefas, entre outras (Abílio, 2019 , p. 3). A presença de algoritmos nas empresas-aplicativo é explicitamente associada aos sistemas opacos e imprevisíveis de gerenciamento e de tomada de decisão automática, substituindo supervisores e gerentes de turno (Mason, 2019). A lógica do algoritmo é desconhecida pelos “parceiros” das plataformas, a quem só resta especular em fóruns virtuais e em mídias sociais sobre seu funcionamento, confabulando sobre táticas para "enganá-lo", como por meio da interrupção do trabalho em massa visando "obrigar" o algoritmo a gerar tarifas mais altas. Contudo, e dentro do contexto aqui observado, a tradicional técnica de interrupção do trabalho perde a conotação de luta contra a exploração, tornando-se uma mera tentativa de gaming the game (ludibriar o jogo algorítmico), o que dá aos trabalhadores um sentimento de controle sobre o processo de trabalho ao mesmo tempo que não demonstra um posicionamento contra a lógica capitalista, apenas contra obstáculos dentro do próprio jogo (Mason, 2019).

É interessante pensar sobre essa colocação à luz das reivindicações dos motofretistas responsáveis pelas paralisações realizadas no mês de julho de 2020, em meio à pandemia de Covid-19, quando os serviços de entrega se tornaram essenciais. Segundo publicação no perfil do Instagram “Treta no Trampo” (@tretanotrampo), do dia 21 de julho de 2020, "a luta é pra ganhar mais, não pra virar CLT ou placa vermelha e acabar ganhando menos. Ninguém quer cumprir hora e ter chefe." O objetivo dos motofretistas é autonomia "pra valer”, o que possibilitaria a negociação do preço do trabalho, afinal não é possível negociar com o aplicativo nem com o algoritmo. Isso se evidencia por meio das punições em caso de recusa de tarefas. Os entregadores e motoristas dos aplicativos reclamam que eles param de tocar, que perdem pontuação e eventualmente são bloqueados. Por um lado, ainda que o desafio imposto aos trabalhadores pelo gerenciamento algorítmico seja evidente, nenhum deles deseja ver seu trabalho regulamentado pela CLT. Por outro lado, a Reforma Trabalhista (Lei n. 13.467/2017) legalizou e passou a fomentar o uberismo (entendido também como informalidade), por meio do reconhecimento do trabalho intermitente (Krein, Abílio, Freitas, Borsari, \& Cruz, 2018), por exemplo. Nesse sentido, além da eliminação das garantias conquistadas por meio do Estado de direito pelo Big Other infotecnológico (Zuboff, 2015), agora o próprio Estado colabora para que essas garantias (entre elas, as trabalhistas) sejam apagadas da legislação vigente.

O gerenciamento algorítmico desponta como uma nova faceta do mundo do trabalho, tendo como estratégia a gamificação e possibilitando, assim, que o trabalho esteja cada vez mais disperso e a sua gestão e controle, cada vez mais concentrados (“organização através da dispersão", Harvey [1992]). A dispersão é representada pela multidão de trabalhadores, disponíveis e engajados, que aderem à empresa-aplicativo, arcam com riscos e custos da sua atividade e não possuem nenhuma garantia, direito ou segurança (Abílio, 2019). Eles também são denominados "trabalhadores just in time“ (Abílio, 2019, p. 4), uma vez que as empresas-aplicativo são empre- 
sas on-demand. A formação de uma multidão de trabalhadores representa um novo estágio da terceirização do trabalho, já que não existem mais subcontratados, mas uma multidão de "parceiros" que constantemente se gerenciam e buscam se diferenciar individualmente por meio de jornadas de trabalho mais longas e assunção de custos maiores. Esses são os empreendedores de si, neossujeitos modulados pela "cultura de empresa" (Dardot e Laval, 2016, p. 328) e que gerenciam o próprio trabalho de maneira subordinada (Abílio, 2019, p. 5).

A governança ou gerenciamento algorítmico torna possível uma previsibilidade maior do comportamento da multidão de trabalhadores, e é justamente essa previsibilidade que torna possível governar a massa, tradicionalmente associada à desordem (Castro, 2018). Das numerosas movimentações monitoradas pelos aplicativos e seus algoritmos, "tiram-se pressuposições sobre padrões futuros, que se projetam sobre o presente, como seu itinerário e guia, provocando a preempção da incerteza pela via da mensurabilidade, que por seu turno pavimenta o caminho para a gestão do risco" (Castro, 2018, p. 175). Nesse sentido, “o capitalismo da informação visa predizer e modificar o comportamento humano como um meio [de] produzir receita e controle de mercado" (Zuboff, 2015, p. 75).

\section{UBERISMO E EXPERIMENTOS GAMIFICADOS}

A gamificação é uma ferramenta que consegue esconder o trabalho embaixo de camadas de desafios e brincadeiras, nos remetendo ao conceito de playbor, neologismo que sinaliza a sobreposição entre trabalho e lazer, produção e consumo, capaz de tornar o trabalho tão viciante quanto jogos de videogame ( $S$ cholz, 2017). 0 caráter experimental das estratégias gamificadas das empresa-aplicativos é enfatizado por autores e comentaristas: Scheiber (2017) escreve sobre a Uber, enquanto Mason (2019) fala sobre sua experiência trabalhando para a Lyft. Scheiber (2017) é explícito ao afirmar que a Uber está furtivamente envolvida em experimentos comportamentais para manipular seus motoristas em prol do crescimento corporativo. Por um lado, a empresa insiste em dizer que seus motoristas estão vinculados por meio de contratos, sendo parceiros ou empreendedores que gozam de flexibilidade e que, por meio da plataforma, se conectam aos consumidores que precisam de seus serviços (mediante o pagamento de uma comissão de entre $20 \%$ e 30\%, segundo Rosenblat e Stark [2016]). Por outro lado, a empresa-aplicativo precisa competir com outras, 0 que significa atender seus consumidores no menor prazo e com o menor custo possíveis. E, como elas não dispõem dos meios de coerção das organizações tradicionais, a gamificação é usada para incentivar comportamentos lucrativos dos seus "colaboradores”, ainda que aquelas possam ser também prejudiciais aos trabalhadores.

Motoristas recebem "mensagens de texto, emails, pop-ups e gráficos cuidadosamente projetados para mantê-los atrás do volante e direcioná-los, ostensivamente, para áreas de maior demanda” (Süsser, Roessler, \& Nissenbaum, 2019, p. 8). Dessa maneira, como em jogos de videogame, os trabalhadores das plataformas são impulsionados discretamente, resultando em mais engajamento emocional e mais investimento na finalização de tarefas. Lembramos, ainda, que o contato com a empresa é feito majoritariamente por meio do aplicativo, sem interação humana, viabilizando que todas as atividades sejam quantificadas e transformadas em dados que são coletados e analisados, sugerindo, assim, a possibilidade de implementação ilimitada das estratégias gamificadas. Elencamos abaixo exemplos dessas estratégias, lembrando que não se trata de um rol exaustivo. Além disso, chamamos atenção para a obsolescência que ronda os estudos sobre novas mídias e as TCl (Crary, 2013), o que sinaliza a ampliação do rol de técnicas gamificadas ao longo do tempo, tornando fundamental uma investigação aprofundada para entender como o universo do trabalho está sendo reconfigurado por meio da aceleração promovida pelas $\mathrm{TCl}$ e as novas formas de gerenciamento e controle do trabalho que emergem nesse contexto.

Além das recompensas imateriais, como os distintivos de motorista divertido (Scheiber, 2017), gráficos elaborados, que mostram aos motoristas áreas nas quais há probabilidade de tarifas mais altas, são considera- 
dos uma técnica de gamificação (Süsser et al., 2019). Os motoristas são atraídos pela possibilidade de corridas mais lucrativas ("preço dinâmico"), mas as chances de conseguir uma são ínfimas e extremamente imprevisíveis, porque as áreas em destaque aparecem e desaparecem em questão de minutos (Mason, 2019). Ao que tudo indica, a tática mantém os motoristas dirigindo para atender a demanda (Calo \& Rosenblat [2017, p. 1662] chamam essa técnica de "mecanismo isca e chibata"). A imprevisibilidade é viciante e muito explorada também em jogos de azar para fazer com que os jogadores façam só mais uma aposta (Mason, 2019).

A manutenção do trabalhador just in time ou on-demand é realizada por meio de técnicas como notificações que são recebidas quando, por exemplo, estão prontos para se desconectar do aplicativo: "Tem certeza de que deseja ficar offline? A demanda é muito alta na sua área. Ganhe mais dinheiro, não pare agora!" (Rosenblat \& Stark, 2016, p. 3768). Outra notificação comum é a que avisa sobre a proximidade de atingir uma meta de ganho arbitrária: "Você está a US\$10 de ganhar US\$330!", acompanhada por comandos logo abaixo da mensagem (e em destaque), que oferecem duas opções ao motorista - se desconectar ou seguir dirigindo (Scheiber, 2017), como uma tela de um jogo de videogame. Essas são "tentativas de explorar uma conhecida vulnerabilidade na tomada de decisão - a preocupação das pessoas com metas" (Süsser et al., 2019, p. 8). Efeitos semelhantes são obtidos por meio do recurso interativo dos aplicativos que mostram aos motoristas "o status do trabalho (horas, ganhos, viagens, etc.) em formatos semelhantes a jogos, conhecidos por seu poder de manter jogadores ao console e, presumivelmente, motoristas ao volante" (Süsser et al., 2019, p. 8).

Uma técnica adotada pela Uber e que é considerada viciante (Mason, 2019; Scheiber, 2017; Süsser et al., 2019) é o despacho de corridas em fila (recurso automático e padrão, que a Uber garante que pode ser desativado pelo motorista, porém é automaticamente reativado após cada pausa, segundo Scheiber [2017]), ou seja, antes de terminar uma corrida, os motoristas são informados de outras solicitações, o que as torna praticamente irresistíveis. Essa técnica é comparável àquela utilizada por serviços de streaming, como Netflix e Amazon Prime, que promove uma nova forma de consumir denominada "binge watching" (e.g. Pittman \& Sheehan, 2015, o "maratonar séries" em português). No âmbito do trabalho uberizado, certamente a técnica promove uma nova (e viciante) forma de trabalhar, o que diminui o tempo de espera para os consumidores enquanto passa por cima do autocontrole dos motoristas (Scheiber, 2017).

Como último exemplo, apontamos o próprio sistema de avaliações que os aplicativos usam para classificar seus motoristas, associado à vigilância e ao gerenciamento do trabalhador. Além de terceirizar a função de gerente para os consumidores (Rosenblat \& Stark, 2016), criando uma economia da reputação (Slee, 2017), as avaliações evidenciam o sistema de monitoramento constante do trabalho dos motoristas com o intuito de identificar e criar fluxos de trabalho eficientes, tal qual na tradição taylorista (Rosenblat \& Stark, 2016, p. 3772). No bojo da tecnocultura, a vigilância é a via de coleta dos dados produzidos por trabalhadores e usuários dos aplicativos. Esses dados viabilizam que outras técnicas gamificadas sejam implementadas, evitando medidas disciplinares diretas por meio do uso métricas semanais de desempenho, por exemplo (Rosenblat \& Stark, 2016, p. 3772). A estabilidade de emprego é ameaçada. Os trabalhadores limitam-se a especular em comunidades nas redes sociais como essas avaliações são feitas. Algumas empresas distribuem as tarefas em faixas de horário de alta demanda de acordo com as avaliações acumuladas. Quando a pontuação cai, as chamadas tornam-se escassas ou os trabalhadores são desligados pela empresa-aplicativo (Ordaz, 2019).

Tentando manter médias altas, os trabalhadores recorrem ao que é descrito como trabalho emocional, a combinação de tentativas amigáveis de conversação com contato visual, visando adivinhar as preferências dos passageiros em troca de boas avaliações em vez de gorjetas (Rosenblat \& Stark, 2016, p. 3775). Além disso, o empenho em agradar os usuários torna-se uma obsessão conforme os relatórios de avaliação chegam e apre- 
sentam queda na média (Mason, 2019). Como as avaliações são calculadas com base nas últimas 100 corridas, os motoristas sentem-se obrigados a dirigir ainda mais em troca de avaliações melhores (Mason, 2019). Abílio (2019, p. 4) aponta que as avaliações atuam como uma certificação informal que afeta a identidade profissional do trabalhador, isto é, seu reconhecimento profissional está intimamente ligado ao seu ranqueamento ao longo do tempo. Logo, até mesmo a possibilidade de acessar trabalhos futuros está em jogo.

Os experimentos conduzidos pelas empresas-aplicativo com seus "parceiros" revelam a "vulnerabilidade humana a formas de pensamento irracional, tendencioso e limitado, bem como tendências a rotinas compulsivas e até viciantes" (Süsser et al., 2019, p. 9). Mason (2019) vai mais longe, sustentando que essas empresas on-demand adotam os mesmos elementos de empresas de apostas com o escopo de manter seus trabalhadores conectados e disponíveis por períodos maiores, checando o aplicativo frequentemente. Em tese, a vigilância contribui ao triangular os dados produzidos a cada interação com outros dados demográficos, formando perfis que permitem que motoristas recebam comunicação personalizada. Contudo, existem autores (e.g. Schüll, 2014) que defendem que o laço lúdico (ludic loop), um sentimento de imprevisibilidade que é viciante, é responsável pela manutenção dos trabalhadores à disposição. Afinal, eles nunca sabem quando surgirão áreas de preço dinâmico nem quando chegará a próxima tarefa que permitirá a conquista do bônus. Assim, os trabalhadores são condicionados a fazer só mais uma corrida, como o jogador que precisa jogar sempre uma última partida. Existe, ao que parece, uma dimensão temporal envolvendo a gestão e controle do trabalho e que se combina com a vigilância e o funcionamento das plataformas que merece ser investigada. Teme-se, assim, um retorno a uma era anterior ao New Deal (Scheiber, 2017), quando vigorava uma assustadora assimetria de poder entre organizações e trabalhadores, representada pela ausência de garantias e seguranças, viabilizando a exploração daqueles. Estamos diante de uma possível servidão digital, que se assemelha muito com as condições de trabalho do século XIX (Ordaz, 2019).

À guisa de conclusão, sinalizamos que o uberismo se afirma como tendência global no mundo do trabalho (Abílio, 2019), aparecendo em outros contextos associados à gig economy, como o trabalho doméstico, o microtrabalho e o online freelancing (Woodcock \& Graham, 2020). Em todos esses cenários, a gamificação opera, modificando a forma da gestão e controle dos trabalhadores. Contudo, estudos recentes aventam a possibilidade de uma economia de plataforma sustentável, bem como do cooperativismo de plataforma (Morrell et al., 2020; Scholz, 2016; Schor \& Eddy, 2020), contextos nos quais o uso de técnicas gamificadas é bastante reduzido: quatro das 20 plataformas que fizeram parte do estudo de Morrell et al. (2020) usam gamificação. Três dessas quatro plataformas são unicórnios (ou seja, startups avaliadas em 1 bilhão de dólares antes de abrirem seus capitais em bolsas de valores), e uma é uma plataforma com design alternativo. Além disso, duas em 20 afirmaram que seus empregados podem rejeitar tanto o gerenciamento algorítmico quanto as técnicas gamificadas quando esses aspectos estiverem presentes (Morrell et al., 2020). Ainda, essas duas plataformas são do tipo alternativo (ou seja, é impossível rejeitar tanto o gerenciamento algorítmico quanto a gamificação quando se trabalha para plataformas digitais unicórnios, segundo Morrell et al. [2020]).

Por seu turno, o cooperativismo de plataforma é pensado a partir dos valores da Economia Social e Solidária e dos princípios do cooperativismo com o intuito de ser uma alternativa verdadeiramente colaborativa (Morrell et al., 2020). Schor e Eddy (2020) investigaram plataformas sem fins lucrativos que visam promover benefícios sociais e que, apesar de usarem a mesma tecnologia, em versões de baixo custo, de outras plataformas, ou não tiveram sucesso, ou tiveram um crescimento bastante lento. De toda forma, a expectativa é que nesses modelos a gamificação seja reduzida ou até mesmo opcional. A tentativa de criar cooperativas de entregadores no Brasil 
existe e conta com o trabalho voluntário de profissionais de diversas áreas (advogados, programadores, economistas, entre outros), apesar do alto custo inicial do desenvolvimento de um aplicativo simplificado (cerca de 500 mil reais, segundo site da revista Época Negócios [2020]).

\section{REFERÊNCIAS}

Abílio, L. C. (2019). Uberização: Do empreendedorismo para o autogerenciamento subordinado. Psicoperspectivas, 18(3), 1-11. doi: 10.5027/psicoperspectivas-vol18-issue3-fulltext-1674

Abílio, L. C. (2020). Plataformas digitais e uberização: Globalização de um Sul administrado? Contracampo, 39(1), 12-26. doi: 10.22409/contracampo.v39i1.38579

Bogost, I. (2011). Gamification is bullshit: My position statement at the Wharton Gamification Symposium. Retrieved from http://bogost.com/writing/blog/gamification_is_bullshit/

Braga, R. (2009). A vingança de Braveman: O infotaylorismo como contratempo. In R. Antunes, \& R. Braga (Orgs.), Infoproletários: Degradação real do trabalho virtual, 59-88 São Paulo, SP: Boitempo.

Bridle, J. (2019). A nova idade das trevas: A tecnologia e o fim do futuro. São Paulo, SP: Todavia.

Caillois, R. (2001). Man, play and games. Champaign, Illinois: University of Illinois.

Calo, R., \& Rosenblat, A. (2017). Taking economy: Uber, information, and power. Columbia Law Review,117(6), 1623-169o. Recuperado de https://columbialawreview.org/ content/the-taking-economy-uber-information-and-power/

Castro, J. C. L. (2018). Redes sociais como modelo de governança algorítmica. MATRIZes, 12(2), 165-191. doi: 10.11606/ issn.1982-8160.v12i2p165-191

Charitsis, V., Zwick, D., \& Bradshaw, A. (2018) Creating worlds that create audiences: Theorising personal data markets in the age of communicative capitalism. Triple C, 16(2), 820834. doi: 10.31269/triplec.v16i2.1041

Crary, J. (2013). 24/7: Late capitalism and the ends of sleep. London, UK: Verso.

Dardot, P., \& Laval, C. (2016). A nova razão do mundo: Ensaio sobre a sociedade neoliberal. São Paulo, SP: Boitempo.

Deleuze, G. (1992). Conversações, 1972-1990. São Paulo, SP: Editora 34 .

Deterding, S., Khaled, R., Nacke, L. E., \& Dixon, D. (2011). Gamification: Toward a definition. Recuperado de http:// gamication-research.org/wp-content/uploads/2011/04/o2Deterding-Khaled-Nacke-Dixon.pdf

Doneda, D., \& Almeida, V. A. F. (2018). O que é a governança de algoritmos? In F. Bruno, B. Cardoso, M. Kanashiro, L. Guilhon, \& L. Melgaço (Orgs.), Tecnopolíticas da vigilância: Perspectivas da margem. São Paulo, SP: Boitempo.

Doorn, N. Van, \& Chen, J. Y. (2020, no prelo). Odds stacked against workers: Labor process gamification on Chinese and American food delivery platforms. Socio-Economic
Review. Recuperado de https://admin.platformlabor.net/ output/labor-process-gamification-china-us-food-deliveryplatforms/Odds\%20Stacked\%20Against\%20Workers_prepub.pdf

Dymek, M., \& Zackariasson, P. (2016a). The business of gamification: A critical analysis. New York, USA: Routledge.

Dymek, M., \& Zackariasson, P. (2016b). Work hard, play hard. In M. Dymek, \& P. Zackariasson (eds), The business of gamification: A critical analysis, [ePub], xi-xxi,New York, USA: Routledge.

Época Negócios. (2020). "Adeus, iFood": Entregadores tentam criar cooperativa para trabalhar sem patrão. Recuperado de https://epocanegocios.globo.com/Carreira/ noticia/2020/07/adeus-ifood-entregadores-tentam-criarcooperativa-para-trabalhar-sem-patrao.html

Escribano, F. (2013). Gamification versus ludictatorship. Revista de Comunicación, 5, 58-72. Recuperado de http:// revistadigitalis.uvic.cat/índex.php/obradigital/article/ view $/ 22$

Filgueiras, V., \& Antunes, R. (2020). Plataformas digitais, uberização do trabalho e regulação no capitalismo contemporâneo. Contracampo, 39(1), 27-43. doi: 10.22409/ contracampo.v39i1.38901

Fuchs, M. (2014). Predigital precursors of gamification. In M. Fuchs, S. Fizek, P. Ruffino, \& N. Schrape (Eds.), Rethinking gamification. Hybrid Publishing Lab, Centre for Digital Cultures, United Kingdom: Lightning Source UK Ltd, 119-140.

Gillespie, T. (2010). The politics of 'platforms'. New Media and Society, 12(3), 347-364. doi 10.1177/1461444809342738

Hamari, J. (2013). Transforming Homo economicus into Homo ludens: A field experiment on gamification in a utilitarian peerto-peer trading service. Electronic Commerce Research and Applications, 12, 236-245. doi: 10.1016/j.elerap.2013.01.004

Harvey, D. (1992). A condição pós-moderna: Uma pesquisa sobre as origens da mudança cultural. São Paulo, SP: Loyola.

Kittur, A., Nickerson, J. V., Bernstein, M., Gerber, E., Shaw, A., Zimmerman, J., Lease, M., \& Horton, J. (2013, February 23-27). The future of crowd work. Proceedings of the ACM Conference on Computer Supported Coooperative Work, San Antonio, USA. Recuperado de https:// hci.stanford.edu/publications/2013/ CrowdWork/futureofcrowdwork-cscw2013.pdf

Koivisto, J., \& Hamari, J. (2014). Demographic differences in perceived benefits from gamification. Computer in Human Behavior, 35, 179-188. doi: 10.1016/j.chb.2014.03.007

Kozinets, R. V. (2019). Consuming tecnocultures: An extended JCR curation. Journal of Consumer Research, 46, 620-627. doi: 10.1093/jcr/uczo34 
Krein, J. D., Abílio, L., Freitas, P., Borsari, P., \& Cruz, R. (2018). Flexibilização das relações de trabalho: Insegurança para os trabalhadores. Revista do Tribunal Regional do Trabalho da 15 ${ }^{\underline{a}}$ Região, (52), 41-66. Recuperado de https://juslaboris.tst. jus.br/handle/20.500.12178/141969

Lemke, T. (2007). An indigestible meal? Foucault, governmentality and state theory. Distinktion, 8(2), 43-64. doi: $10.1080 / 1600910 X .2007 .9672946$

Manyika, J., Lund, S., Bughin, S., Robinson, K., Mischke, J., \& Mahajan, D. (2016, October). Independent work: Choice, necessity, and the gig economy. Mckinsey Institute. Retrieved from https://www. mckinsey.com/featured-insights/employment-and-growth/independent-work-choice-necessity-and-the-gig-economy

Mason, S. (2019). Chasing the pink. Logic, 6. Recuperado de https://logicmag.io/play/chasing-the-pink

McGonigal, J. (2011). Reality is broken: Why games make us better and how they can change the world. New York, USA: Penguin Books.

Moreschi, B., Pereira, G., \& Cozman, F. G. (2020). The Brazilian workers in Amazon Mechanical Turk: Dreams and realities of ghost workers. Contracampo, 39(1), 46-64. doi: 10.22409/ contracampo.v39i1.38252

Morozov, E. (2018). Big Tech: A ascensão dos dados e a morte da política. São Paulo, SP: Ubu Editora

Morrell, M. F., Espelt, R., \& Cano, M. R. (2020). Sustainable platform economy: Connections with the sustainable development goals. Sustainability, 12(18), 7640. doi: $10.3390 /$ su12187640

Ordaz, P. (2019). Os entregadores de comida são reféns do seu 'like'. Recuperado de https://brasil.elpais.com/ brasil/2019/01/23/economia/1548260634_440077.html

Pittman, M., \& Sheehan, K. (2015). Sprinting a media marathon: Uses and gratifications of binge-watching television through Netflix. First Monday, 2o(10). doi:10.5210/fm.v20i10.6138

Pridmore, J., \& Zwick, D. (2011). Editorial: Marketing and the rise of commercial consumer surveillance. Surveillance and Society, 8(3), 269-277. Recuperado de https://ojs.library. queensu.ca/index.php/surveillance-and-society/article/ view $/ 4163 / 4165$

Rosenblat, A., \& Stark, L. (2016). Algorithmic labor and information asymmetries: A case study of Uber's drivers. International Journal of Communication, 10, 3758-3784. Recuperado de https://ijoc.org/index.php/ijoc/article/ view/4892/1739

Santos, J. V. (2020). Uberismo e gaificação: Transformações do mundo do trabalho reveladas na greve dos entregadores. Instituto Humanitas Unisinos. Recuperado de http://www. ihu.unisinos.br/159-noticias/entrevistas/601125-uberismoe-gamificacao-transformacoes-do-mundo-do-trabalhoreveladas-na-greve-dos-entregadores-entrevista-especialcom-ana-claudia-moreira-cardoso
Scheiber, N. (2017). How Uber uses psychological tricks to push its drivers' buttons. N.Y. Times. Recuperado de https://www. nytimes.com/interactive/2017/04/02/technology/uberdrivers-psychological-tricks.html

Scholz, T. (2016). Cooperativismo de plataforma: Contestando a economia do compartilhamento corporativa. São Paulo, SP: Autonomia Literária.

Scholz, T. (2017). Uberworked and underpaid: How workers are disrupting the digital economy. Cambridge, UK: Polity Press.

Schor, J. B., \& Eddy, S. (2020). The just and democratic platform? Possibilities of platform cooperativism. Recuperado de https://www.bc.edu/content/dam/bc1/schools/mcas/ sociology/pdf/connected/Platform $\% 2$ oPossibilities $\% 20$ March\%201\%202020.pdf

Schüll, N. D. (2014). Addiction by design: Machine gambling in Las Vegas. Princeton, USA: Princeton University Press.

Slee, T. (2017). Uberização: A nova onda do trabalho precarizado. São Paulo, SP: Editora Elefante.

Srnicek, N. (2017). Platform capitalism [ePub]. Cambridge, UK Polity Press.

Stefano, V. De. (2017). Labour is not a technology: Reasserting the declaration of Philadelphia in times of platform-work and gig-economy. IUSLabor, 2, 1-16. Recuperado de https://core. ac.uk/download/pdf/155003521.pdf

Süsser, D., Roessler, B., \& Nissenbaum, H. (2019). Online manipulation: Hidden influences in a digital world. Georgetown Law Techonology Review, 4(1), 1-45. Recuperado de https:// georgetownlawtechreview.org/online-manipulation-hiddeninfluences-in-a-digital-world/GLTR-01-2020/

Valenduc, G. (2019). New form of work and employment in the digital economy. In A. Serrano-Pascual, \& M. Jespen (Eds.), The deconstruction of employment as a political question. Brussels, Belgium: Palgrave Macmillan, 63-80.

Vesa, M., Hamari, J., Harviainen, J. T., \& Warmelink, H. (2017). Computer Games and Organization Studies. Organization Studies, 38(2), 273-284. doi: 10.1177/0170840616663242

Vesa, M., \& Harviainen, J. T. (2019). Gamification: Concepts, consequences, and critiques. Journal of Management Inquiry, 28(2), 128-130. doi: 10.1177/1056492618790911

Woodcock, J. \& Graham, M. (2020). The Gig Economy: A critical introduction [ePub]. Cambridge, UK: Polity Press.

Woodcock, J., \& Johnson, M. R. (2018). Gamification: What it is, and how to fight it. The Sociological Review, 66(3), 542-558. doi: $10.1177 / 0038026117728620$

Zichermann, G., \& Cunningham, C. (2011). Gamification by design: implementing game mechanics in web and mobile apps. Canada: O’Reilly Media, Inc.

Zuboff, S. (2015). Big Other: Surveillance capitalism and the prospects of an information civilization. Journal of Information Technology, 3o(1), 75-89. doi: 10.1057/jit.2015.5

\section{CONTRIBUIÇÃO DA AUTORA}

Renata Couto de Azevedo de Oliveira trabalhou na pesquisa, na redação e na revisão final do manuscrito deste ensaio teórico. 